\title{
A NEOFOBIA JURÍDICA DO ESTADO NO TOCANTE AO MODELO GESTOR DA SEGURANÇA PÚBLICA NACIONAL: AVANÇOS E DESAFIOS NA PRESTAÇÃO DO SERVIÇO PÚBLICO DE SEGURANÇA NO BRASIL
}

\author{
THE "LEGAL AVERSION TO CHANGES" STATE IN TOUCHING THE MODEL \\ MANAGER OF PUBLIC SECURITY NATIONAL: ADVANCES AND \\ CHALLENGES IN THE PROVISION OF PUBLIC SERVICE SECURITY IN \\ BRAZIL
}

\author{
${ }^{1}$ Guilherme Barbosa da Silva \\ ${ }^{2}$ Vanessa Rui Fávero
}

\section{RESUMO}

No que tange à segurança pública nacional, assevera-se que os atuais modelos gestores convencionais não conseguem mais lidar de forma eficaz com a escalada da violência e do crime, de forma a impulsionarem a necessidade de transformações mais amplas na vida social contemporânea, para dar conta da complexidade e da fragmentação da realidade social da segurança pública brasileira. Para a adequada prestação de serviços de segurança pública, é necessária a eleição de uma política pública de segurança compromissada e eficaz que deve ser coerentemente realizada, com foco na efetiva pacificação social dos conflitos; de forma que o paradigma repressivo deve ser enfim deixado de lado; cindindo, dessa forma, com o intitulado neofobismo jurídico estatal no tocante à segurança pública nacional, uma vez que não basta à mera transmissão de uma falsa sensação de segurança à sociedade através de reinvestimentos no atual modelo gestor reativo-repressivo com o aumento da repressão estatal, sem examinar mais a fundo toda a problemática dos conflitos sociais, que deve, antes de tudo, analisar macroestruturalmente fatores como a política criminal até então adotada, o atual foco da prestação dos serviços de segurança pública postos a disposição da população e a sua efetividade para, dessa forma, através de análises engajadas com a realidade social vigente, e, utilizando-se da pesquisa bibliográfica, bem como do método dedutivo-indutivo , propor novos paradigmas gestores da segurança pública que se coadunem com um modelo sustentável de Direito e política, compromissados com uma efetiva pacificação social dos conflitos.

Palavras-chave: Sistema penal repressivo, Estado jurídico neófobo, Novos paradigmas, Via preventiva, Efetiva pacificação social

\footnotetext{
${ }^{1}$ Mestre em Ciências Jurídicas pela Universidade Estadual do Norte do Paraná - UENP, Jacarezinho - PR (Brasil). Professor da Faculdade do Norte Pioneiro - FANORPI, Santo Antônio da Platina - PR (Brasil).

E-mail: guilhermebarbosaadv@ hotmail.com

${ }^{2}$ Mestre em Ciências Jurídicas pela Universidade Estadual do Norte do Paraná - UENP, Jacarezinho - PR (Brasil)

E-mail: vanessa_vrf@hotmail.com
} 


\begin{abstract}
Regarding the national public security, it is stated that current conventional models managers can no longer deal effectively with the escalation of violence and crime in order to push forward the need for broader changes in contemporary social life, to account the complexity and fragmentation of social reality of Brazilian public security. For proper delivery of public security service, it is necessary for the election of a committed and effective public security policy that must be consistently held, focusing on effective social pacification of conflicts; so that the repressive paradigm should be finally left side; splitting thus entitled to the "legal aversion to change" state with regard to national public security, since not just the mere transmission of a false sense of security to society through reinvestment in the current model reactive-repressive manager - with increasing repression State - without detailed examination of the whole issue of social conflicts, which must first of all examine in a general way factors such as criminal policy so far adopted, the current focus of the provision of public safety services made available to the population and the its effectiveness to thus - through analysis engaged with current social reality, and, using the literature and the deductive-inductive method - propose new public safety managers paradigms that are consistent with a sustainable model of "law and policy" committed to an effective social pacification of conflicts.
\end{abstract}

Keywords/Palabras-claves/Mots-clés: Repressive penal system, Legal state aversion to change, New paradigms, Preventive way, Effective social pacification 


\section{INTRODUÇÃO}

Atualmente, é facilmente perceptível que os atuais modelos convencionais gestores da segurança pública nacional, classicamente consagrados, não conseguem mais lidar de forma eficaz com a escalada da violência e do crime; de forma a impulsionarem a necessidade de transformações mais amplas na vida social contemporânea, para dar conta da complexidade e da fragmentação da realidade social da segurança pública brasileira. Isso porque, ao direcionarem esforços para o tratamento da problemática da resolução de conflitos sociais - com a definição das prioridades na prestação dos serviços públicos a serem proporcionados nessa área -, o Estado insiste em investir no modelo reativo-repressivo convencional, quando este, há tempos, já se demonstra inadequado e fadado ao insucesso, uma vez que sobrecarrega, cada vez mais, o sistema penal brasileiro.

Assim, a ausência de atuação estatal em setores essenciais da sociedade para a contenção de conflitos sociais - que merecem primordial cautela em seu tratamento - acaba por acarretar, diante da ausência de atuação das demais formas de controle social, uma exacerbada utilização da tutela penal, que deveria ocupar-se tão somente com os bens jurídicos essenciais e de especial fundamentalidade para a vida em sociedade, assumindo, deste modo, funções que não lhe deveriam caber.

Dado o exposto, podemos afirmar, dessa forma, que como pano de fundo da segurança pública brasileira nós nos depararíamos com um verdadeiro "Estado Jurídico Neófobo"; no qual se destacaria a baixa capacidade do Estado brasileiro em se adaptar às mudanças que ocorrem na sociedade - e as consequentes demandas na solução de seus conflitos - , resistindo às inovações e mantendo-se preso a paradigmas jurídicos que não têm como foco principal a pacificação desses conflitos sociais.

Portanto, o cenário no qual desenvolve-se a pesquisa, ora em pauta, é a falência do atual sistema de segurança pública nacional, que mesmo com resultados concretos acerca disso, insiste no reivestimento de verbas no atual modelo reativo-repressivo ao invés da adoção de novos paradigmas preventivos e multifuncionais, em uma insistente aversão a mudanças.

Neste contexto, interessante expressão passou a ser cunhada e inserida também no campo da política de segurança pública; consistente no intitulado "efeito Rainha Vermelha" utilizado inicialmente pelo biólogo americano Leiggt Van Valen, para designar o princípio da 
"mudança zero" em que predador e presa se deslocariam na mesma velocidade - ilustrando o fato de que, no atual modelo gestor reativo-repressivo da segurança pública nacional, mesmo quando os esforços policiais são desenvolvidos em sua intensidade máxima, redundam em "lugar nenhum" devido a insistência no clássico modelo reativo-repressivo adotado, que há tempos já não vem mais surtindo os efeitos esperados.

Assim, averigua-se que o problema é que o Estado tenta solucionar, através de uma política penal - e não através de uma política criminal -, o problema da criminalidade; o que acaba refletindo na prestação do serviço público de segurança; e, partindo-se deste pressuposto, a pesquisa desenvolveu-se em três momentos.

Primeiramente, a pesquisa focou na prestação do serviço de segurança pública no Brasil, trazendo como pano de fundo para ambientação a intitulada "Síndrome da Rainha Vermelha" e a insistência no modelo reativo-repressivo, que já não surte os efeitos esperados no tratamento da problemática dos conflitos sociais.

Em ato contínuo, em um segundo momento, analisou-se a importância da eleição de uma política de segurança pública adequada que, consequentemente, refletirá no correto direcionamento para a prestação de serviços públicos adequados às demandas sociais. E, por fim, tratou-se da apresentação de novos paradigmas de gestão da segurança pública - fora das „lentes"e de um "Estado Jurídico Neófobo" -, trazendo, como propostas viáveis, mecanismos alternativos a serem aliados à prestação dos serviços públicos que sejam eficazes no tratamento da realidade social fática pela via participativa e preventiva, em contraponto à repressiva, modelo atualmente adotado.

Entretanto, tal via preventiva é ainda considerada um desafio que requer inúmeros avanços na prestação do serviço público de segurança atual por implicar em prestações positivas, contribuições e esforços solidários que devem buscar neutralizar as situações de desequilíbrio e conflitos sociais através de medidas efetivas no enfrentamento das causas do problema.

Dessa forma, por meio de análises engajadas com a realidade social vigente, buscouse - através da pesquisa bibliográfica e do método dedutivo-indutivo -, a apreciação de que o objetivo último de uma eficaz política de prevenção ao delito, para a adequada prestação do serviço público de segurança, inicia-se pela implementação de direitos sociais básicos do cidadão, tais como saúde, educação de qualidade, trabalho, moradia digna, dentre outros; sem os quais, quaisquer outras medidas de política criminal eleitas pelo Estado como forma de contenção dos conflitos sociais, seriam apenas paliativas, sem encarar, de fato, a problemática 
a ser enfrentada; uma vez que, para construir uma cultura de paz é preciso mudar atitudes, crenças e comportamentos por parte de todos, buscando, assim, mecanismos alternativos mais amplos de desconstrução de conflitos, destinados a transformar padrões de comportamento e a estimular o convívio em um ambiente cooperativo, no qual, uma efetiva pacificação social possa se dar sem confronto em demasia e de modo não adversarial.

\section{SERVIÇO DE SEgURANÇA PÚBLICA NO BRASIL E A "SÍNDROME DA RAINHA VERMELHA"}

Inicialmente cabe pontuar que serviços públicos são espécies de utilidade ou comodidade material que podem até serem fruíveis singularmente, mas que sempre buscarão satisfazer necessidades coletivas cujo Estado tem o dever de prestar ao assumir como tarefa sua, podendo a prestação deste serviço se dar de forma direta ou indireta, seguindo sempre o regime jurídico de direito público total ou parcialmente; o que também podemos averiguar ao adentrar nas entranhas da prestação do serviço de segurança no Brasil.

Maria Sylvia Zanela Di Pietro (2011, p.99), destaca que "Não é tarefa fácil definir o serviço público, pois a sua noção sofreu consideráveis transformações no decurso do tempo, quer no que diz respeito a seus elementos constitutivos, quer no que concerne a sua abrangência" e acaba o fazendo por exclusão, conceituando-o em sentido amplo e em sentido estrito.

Assim a citada autora assevera que "Restrito são os conceitos que confinam o serviço público entre as atividades exercidas pela Administração Pública, com exclusão das funções legislativa e jurisdicional; e, além disso, o consideram como uma atividade administrativa, perfeitamente distinta do poder de polícia do Estado” (PIETRO, 2011, p.100)

Nesta árdua tarefa, por sua vez, nas palavras de Celso Antônio Bandeira de Melo, temos um conceito com delimitações mais acentuadas:

\footnotetext{
Serviço púbico é toda atividade de oferecimento de utilidade ou comodidade material destinada a satisfação da coletividade em geral, mas fruível singularmente pelos administrados, que o Estado assume como pertinente a seus deveres e presta por si mesmo ou por quem lhe faça as vezes, sob um regime de Direito Público portanto, consagrador de prerrogativas de supremacia e de restrições especiais -, instituído em favor dos interesses definidos como público no sistema normativo. (MELLO, 2010, p. 679)
} 
Já adentrando, de fato, na seara da segurança pública nacional, para ambientar mais pontualmente a prestação do serviço público de segurança; no que tange às características do serviço de segurança pública, em si, Valter FoletoSantin preleciona que:

O fornecimento do serviço de segurança pública é um serviço primário, essencial, de relevância pública, de uso comum (utiuniversi), em caráter geral, beneficiando todos os cidadãos e a população fixa ou flutuante. Visa tutelar a segurança da população, em face da necessidade do Estado de garantir a defesa da vida, saúde e patrimônio do cidadão, bens jurídicos ameaçados pela prática do delito (art. 144, caput $_{3} \mathrm{CF}$ ). O bem jurídico imediato tutelado é a segurança pública; o mediato, é a ordem pública, o cidadão e o patrimônio. (SANTIN, 2013, p. 71)

Assim, dentro dessa seara de análise trazida, outro conceito de fundamental importância, que se mostra essencial para uma eficaz compreensão do conceito do serviço público de segurança trazido, é a expressão “ordem pública”. Assim, nas palavras de De Plácido da Silva, temos que, ordem pública:

é a situação e o estado de legalidade normal, em que as autoridades exercem suas precípuas atribuições e os cidadãos a respeitam e acatam, sem constrangimento ou protesto. Não se confunde com a ordem jurídica, embora seja uma consequência desta e tenha sua existência formal justamente desta derivada. (SILVA, 1999, p.577)

Agrega-se ainda a tal conceituação o fato de que, nessa seara, para Álvaro Lazzarini (2000, p.09), não é a ordem pública que está a integrar o vasto conceito de segurança pública - valor comunitário - pois, o que ocorre é que a segurança individual e a comunitária, situamse dentro do conceito maior do que seja a ordem pública. Vejamos:

A noção de ordem pública, em verdade, é mais fácil de ser sentida que definida e resulta, no dizer de Salvat, citado em acórdão do Supremo Tribunal Federal, de um conjunto de princípios de ordem superior, políticos, econômicos, morais e algumas vezes religiosos, aos quais uma sociedade considera extremamente vinculada à existência e conservação da organização social estabelecida. A oca, portanto, obedece a um critério contingente, histórico e nacional. (LAZZARINI, 2000, p. 177)

Partindo, dessa forma, do pressuposto de que a segurança pública - e por conseguinte a prestação desse serviço público -, está inserido em um conceito maior, qual seja, o de ordem pública, mais uma vez torna-se essencial recorrermos a fixação de uma eficiente conceituação de segurança pública; e De Plácido Silva muito bem o faz ao esmiuçar que segurança pública, em suas palavras consiste:

[...] no afastamento, por meio de organizações próprias, de todo o perigo, ou de todo mal que possa afetar a ordem pública, em prejuízo da vida, da liberdade o do direito de propriedade do cidadão. A segurança pública assim, limita as liberdades individuais, veda, não pode ir além da liberdade assegurada aos demais, oferecendoa. É de competência da União organizar e manter os seus órgão e instituições e a compete também legislar sobre a matéria. É dever do Estado e responsabilidade de todos. Exerce-se para a preservação da ordem pública e da incolumidade das pessoas e do patrimônio. (SILVA, 1999, p.740) 
Assim, temos que a prestação de tal serviço público será estatal quando a segurança pública é, de fato, prestada pelo Estado, cumprindo a sua obrigação constitucional, e será privado quando exercido pelo povo, em auxílio ao Poder Público e na segurança privada, tendo o Estado o dever de realizar a atividade e o povo tem o direito de participar do serviço na busca por maior sensação de segurança, que seja.

Ainda neste diapasão, o serviço de segurança pública, pode ser primário quando desempenhado pelo Estado ou secundário quando na atuação privada; sendo obrigatório quando fornecido pelo Estado; bem como integral, quando executado inteiramente por este ente estatal.

Por fím, será o serviço de segurança pública considerado eficiente quando for desempenhado a contento, apresentando bons resultados na função de segurança pública individual e coletiva, no controle da criminalidade e na transmissão de sensação de segurança à população; e, em contrapartida será ineficiente quando o resultado for inadequado, insatisfatório, irregular, deficiente, descontínuo e de baixa qualidade, não sendo apto a proporcionar a necessária sensação de segurança ao povo para a vida tranquila em sociedade..

Em uma compilação dessas características, Valter FoletoSantin traz, de forma sistemática, uma classificação dos serviços de segurança pública, subdividindo-o em estatal ou privado; principal ou secundário; obrigatório ou facultativo; integral ou parcial; eficiente ou ineficiente. Vejamos:

\footnotetext{
O serviço de segurança pública é principal quando desempenhado pelo Estado; secundário na atuação privada. É obrigatório quando fornecido pelo Estado, facultativo se exercido pelo particular. É integral quando executado inteiramente; parcial quando não prestado completamente. É eficiente quando desempenhado a contento, com um bom resultado na função de segurança pública, no controle da criminalidade e na transmissão de sensação de segurança à população. Ineficiente quando o resultado é inadequado, insatisfatório, descontínuo e de baixa qualidade, não apto a proporcionar sensação de segurança ao povo para a vida tranqüila em sociedade. (SANTIN, 2013, p. 71)
}

Diante da realidade social vigente, hoje já é facilmente perceptível que a ausência de atuação estatal em setores essenciais da sociedade para a contenção de conflitos sociais - que merecem primordial cautela em seu tratamento - acaba por acarretar, diante da ausência de atuação da demais formas de controle social, uma exacerbada utilização do Direito Penal, que deveria tutelar apenas bens jurídicos fundamentais para a vida em sociedade, que acaba por assumir, dessa forma, funções que não lhe deveriam caber para atender aos anseios da sociedade que clama por paz social. 
Neste contexto, Valter Foleto Santin, afirma com razão que "O Estado é o agente principal pelo serviço de segurança pública, utilizando-se dos órgãos policiais para o desempenho da sua incumbência funcional." (SANTIN, 2013, p. 78) e a prestação do serviço público de segurança passa a estar intimamente ligada com a política criminal a ser adotada.

A política criminal, em si, consagrou-se como uma ciência que cria medidas de combate à violência, tanto pela prevenção, quanto pela repressão e que através de decisões políticas desenvolve meios e técnicas para diminuir e controlar os "desvios" da sociedade, tendo, também e essencialmente, o papel de analisar a realidade social, os delitos e os desvios sociais para propor medidas eficazes em seu tratamento. ${ }^{1}$

Assim, diante de uma sociedade que vê no sistema penal uma importantíssima forma de controle social - atribuindo-lhe, em alguns momentos, até mesmo maior relevância do que deveria possuir - essencial demonstra-se a importância da tomada de decisões políticas que direcionarão o modo de atuação das mais diversas formas de composição dos conflitos sociais. Tais decisões quando eleitas de forma engajada com a realidade social, podem fazer parte de uma política criminal consistente e eficaz no tratamento da problemática social a que se destina tutelar.

Segundo Valter Foleto Santin (2005, p. 209) “A criminalidade não é estática, fato que pressupõe a necessidade de dinamismo na fixação e alteração da política de segurança pública e no seu plano de ação, para a efetiva prestação de serviço de prevenção e combate das práticas delituosas"; o que demonstra a necessidade da adoção de medidas interdisciplinares no tratamento da problemática a ser enfrentada.

Dessa forma, para que a eleição de uma política criminal ocorra de forma eficaz no tratamento das demandas sociais existentes em nossa sociedade, demonstra-se essencial uma análise engajada com a realidade social fática, partindo inicialmente de políticas públicas fortes e consistentes, que busquem efetivar um sistema penal coerente, garantidor dos direitos humanos e promovedor dos valores essenciais da humanidade; e para que consigamos atingir de forma eficaz toda a sistemática penal, imprescindível faz-se que iniciemos pensando em políticas públicas que antecedam a prática da infração penal, gênese do sistema, garantindo condições existenciais mínimas de uma vida digna a todos.

Ademais, é entendimento de Bismael B. de Moraes que "A prevenção é um bem para todos, enquanto a repressão é conveniente para alguns" (MORAES, 2000, p.89). Tal

\footnotetext{
1 A política criminal, segundo Eugênio Raul Zaffaroni e José Henrique Pierangeli, guia as decisões tomadas pelo poder político, bem como proporciona argumentos para criticar essas decisões, cumprindo, portanto, a função de guia e de crítica. (2004, p.129).
} 
apontamento é uma forma de alertar sobre a facilidade de se privilegiar a repressão em detrimento da prevenção; uma vez que a primeira se mostra mais atraente aos olhos imediatistas de quem quer resultados aparentes.

Nesta seara, temos interessante expressão intitulada de "efeito Rainha Vermelha" que foi criada pelo biólogo americano Leiggt Van Valen, inicialmente para designar o princípio da "mudança zero", e posteriormente adaptado no campo da segurança pública por Marcos Rolim como a "síndrome da Rainha Vermelha", que ilustraria o fato de que, mesmo quando os esforços policiais são desenvolvidos em sua intensidade máxima, redundam em lugar nenhumdevido ao modelo reativo adotado.

Trazendo a baila tal cenário selecionado para ambientar o tratamento da prestação do serviço de segurança pública; ele se utiliza de uma famosa passagem de Alice no País das Maravilhas para cunhar tal expressão. Vejamos:

\begin{abstract}
Uma passagem bastante conhecida de através do espelho, de Lewis Carroll, relata o episódio do encontro de Alice com a Rainha Vermelha em um cenário bucólico que evoca a imagem de um imenso tabuleiro de xadrez a céu aberto. Essa passagem deu origem ao que Richard Dawkins (em $O$ relojoeiro cego), a expressão "efeito Rainha Vermelha", cunhado pelo biólogo americano Leigh van Valen para designar o princípio de "mudança zero" na taxa de êxito alcançado independentemente do progresso evolutivo, por exemplo quando o predador e a presa evoluem na mesma proporção e ritmo de tal forma que os melhoramentos alcançados por um e por outro se "anulam"." (ROLIN, 2006, p.37)
\end{abstract}

Dessa forma, Marcos Rolim ao se aproveitar dessa sugestão para cunhar a expressão "Síndrome da Rainha Vermelha” emprega seus reflexos também na seara da segurança pública nacional e demonstra ser terreno fértil para os estudos desse serviço público, ao qual apregoa-se a necessidade de desvinculação do modelo clássico reativo já a tanto tempo utilizado para a adoção de novos paradigmas eficazes no tratamento da problemática social vigente.

Almejando novos paradigmas, este mesmo autor propõe direcionar os holofotes para a prevenção e exprime que:

\footnotetext{
A intervenção racional das forças policiais, em parceria com entidades da sociedade civil, pode alterar várias das condições que são preditivas do crime e da violência. Por conta disso, o ponto central desse novo modelo deve ser a prevenção.(ROLIN, 2006, p.65)
}

Marco A. Florêncio Filho ao deparar-se com tal sistemática observa que "O problema é que o Estado tenta solucionar, através de uma política penal, e não de uma política 
criminal, o problema da criminalidade, levando a cabo um aumento na quantidade de pena e de crimes" (2007, p. 168); de forma que acaba se utilizando cada vez mais do direito penal na resolução de situações que seriam facilmente solucionadas por outros ramos do direito; acreditando que através do recrudescimento do sistema e pela positivação de normas penais irá tratar do fenômeno criminal.

Ao recorrermos aos ensinamentos de Cesare Beccaria, temos que em sua clássica obra Do delito e das penas,este, já prelecionava, há muito tempo atrás, a importância do escopo preventivo a ser encampado por toda boa legislação - o que também se estende à eleição de um serviço público de segurança eficiente -, de forma que, há séculos, o ilustre autor já lecionava que:

Todo legislador sábio deve, antes de mais nada, procurar impedir o mal do que repará-lo; pois uma boa legislação não é mais do que a arte de propiciar aos homens a maior soma de bem-estar possível e livrá-lo de todos os pesares que se lhes possam causar. (BECCARIA, 1999, p. 131).

Dessa forma, não só a atividade legislativa, mas também a eleição de uma política de segurança pública compromissada e eficaz deve ser coerentemente realizada; e o paradigma repressivo deve ser enfim deixado de lado, cindindo com a neofobia do Estado, pois não basta a mera transmissão de uma falsa sensação de segurança à sociedade, sem examinar mais a fundo a problemática que deve, antes de tudo, buscar solucionar de forma efetiva a gênese dos conflitos sociais em questão.

Por melhor que demonstre ser o tratamento do direito penal na contenção da criminalidade, não é com leis que se reprime o crime. O crime é uma ato humano que não deixa de estar relacionado com acontecimentos de ordem política, econômica e social, devendo assim a criminalidade ser enfrentada através de uma política criminal bem definida, que procure enfrentar o problema sem passionalismos.

Afirma Virgílio Luiz Donnici, que "para a manutenção da ordem pública não basta o cumprimento da lei, e ela tem valor extraordinário como fator de equilíbrio social quando efetiva, mas, acima de tudo, uma política de defesa social” (DONNICI, 1976, p. 241), de forma que não basta a positivação de normas jurídicas penais, que embora de fundamental importância para a coesão social quando efetivas, não se sustentam sozinha se desalijada de uma política de defesa social engajada com a realidade social - e efetivada através da prestação de serviços públicos adequados - que a dê sustentação e eficácia. 


\section{ELEIÇÃO DE UMA POLÍTICA DE SEGURANÇA PÚBLICA ADEQUADA}

Em se tratando da prestação do serviço público de segurança, não há como este ocorrer desvinculado de uma política de segurança pública adequada e, neste contexto, Carlos Alberto Baptista muito bem expõe a fragmentariedade do sistema de gestão dos delitos através da supervalorização da legislação penal eleita como mecanismo eficaz para fazer frente ao fenômeno criminal. Vejamos:

Como num corpo humano, se um órgão não desempenha inteiramente a função para a qual se destina, acaba por sobrecarregar outros que, inevitavelmente, esfalfados, entram em crise e se não tratados como um todo que são, morrem aos poucos. Não é mais possível tratar o corpo da segurança pública apenas sintomaticamente. (2007, p.143)

Ao afirmar que "não é mais possível tratar o corpo da segurança pública apenas sintomaticamente", Baptista quer chamar atenção para a opção repressiva enveredada pelo Estado, que por meio do sistema penal remedeia as manifestações de conflito social. Expõe assim que o Estado acaba optando por cuidar dos sintomas manifestados através do delito, e faz isso depositando, de pronto, nas costas da atividade policial a obrigação de responsabilizar-se pela contenção do delito, o que acaba por desencadear a movimentação da estrutura de toda a máquina judicial, sem antes buscar alternativas em outras formas de controle social que visem atingir o problema em suas causas.

Delineia-se, assim, o insucesso do modelo reativo de gestão da segurança pública nacional e sua consequente ineficácia no tratamento da problemática crescente dos conflitos sociais.

No tocante à formulação de uma política de segurança pública com aferição da eficiência dos serviços policiais e de segurança, temos como órgão responsável pela articulação e coordenação da política de segurança nacional o CONASP:

O CONASP encarregado de estabelecer diretrizes, elaborar normas e articular a coordenação da política nacional de segurança pública, desenvolve estudos e ações visando aumentar a eficiência dos serviços policiais e de segurança. (SANTIN, 2013, p. 66)

A título de esclarecimento, a CONASP é um órgão subordinado ao Ministério da Justiça, sendo diretor das Secretarias de Segurança Pública dos Estados.

Neste contexto, não se deve jamais perder de vista que se as demais formas de controle social não agem os órgãos encarregados pela gestão da segurança pública nacional, e, 
de forma correlata, o direito penal - que deveria tutelar apenas bens jurídicos fundamentais para a vida em sociedade, funcionando como ultima ratio -, acaba inflando frente à sua função dando lugar certo a um sistema penal simbólico e punitivista, o que acaba por desencadear a vigente hipertrofia legislativa; como uma das formas de controle social frente à atual crise das instituições sociais, devido à carência de políticas públicas que o coloque freios, o que, sem dúvida alguma, acaba, consequentemente, influindo na prestação dos serviços públicos de segurança.

$\mathrm{Na}$ atual dinâmica de atuação de nosso sistema penal e da política de segurança pública brasileira, temos a erronia utilização da função legislativa do Estado, através da elaboração de leis penais desenfreadamente, utilizando-se do recrudescimento do sistema penal como alternativa viável para solucionar o problema com a disseminação apenas de uma maior "sensação" de segurança, quando assim não deveria ocorrer. Vejamos:

\footnotetext{
Assim, o Direito Penal passa a ser utilizado como instrumento de crueldade e vingança, que surge no seio da sociedade quando diante de casos atrozes, clama por uma punição simbólica para aquele infrator. Criam-se estereótipos de criminalidade, o que reforça a ideia de recrudescimento das estruturas repressivas como forma de vender a sensação de segurança promovida pelo Estado. (KAZMIERCZAK, 2010, p.70)
}

Levando-se em conta o caráter instrumental da violência e da criminalidade aparente que se faz presente cotidianamente nos noticiários para toda a sociedade, podemos visualizar nos anseios sociais as expectativas depositadas em um direito penal que clama por uma legislação repressiva e penalizadora, expressão máxima da utilização daquela intitulada "violência institucional legitimadaee do sistema penal vigente, que tem privilegiado ações repressivas em detrimento da prevenção através de políticas públicas engajadas com a realidade social vigente.

Tendo em vista esse contexto, Eugenio RaúlZaffaroni e Edmundo Oliveira ao tratarem de criminologia e de política criminal constatam tal fato e trazem a tona quatro pertinentes apontamentos, dividindo a crítica ao direito penal em quatro ordens: a) a do exercício real da repressão, abrangendo o processo de criminalização secundária, mais amplo, e que implica na opressão do dominante sobre o oprimido; b) a criminalização primária, representada pela legislação repressiva ou penal; c) o discurso jurídico-penal ou ideológico; e, d) a propaganda do sistema penal, que se apresenta pela opinião pública (ZAFFARONI, OLIVEIRA 2010, p. 07-08). 
Dentro dessas quatro ordens de crítica ao direito penal trazida por Zaffaroni, importante delimitar, como principal foco para maiores reflexões, exatamente, o viés da criminalização primária conduzida por uma legislação eminentemente repressiva diante do clamor social, que vem reforçar o imediatismo do nosso país no tratamento da criminalidade aparente, em que se discutem os efeitos da violência sem analisar as suas causas. Em decorrência disso, acaba-se sempre, consequentemente, chegando à discussão de como reprimir, mas não no como prevenir, sendo essa uma tática que acaba por desviar o foco das reais causas do problema.

Ao tratar do "princípio da intervenção" mínima que deve ser encampada pelo direito penal, César Roberto Bitencourt traz a baila também o fenômeno da inflação legislativa, que leva ao descrédito do direito penal:

\footnotetext{
Os legisladores contemporâneos - tanto de primeiro como de terceiro mundo - tem abusado da criminalização e da penalização, em franca contradição com o princípio em exame ao descrédito não só do Direito Penal, mas a sanção criminal, que acaba perdendo sua força intimidativa diante da "inflação legislativa" reinante nos ordenamentos positivos. (2009, p. 14).
}

Evidencia-se com frequência que a mudança na seara normativa, dissociada dos demais aparelhos de contenção da criminalidade e desalijado de uma eficiente prestação de serviços públicos de segurança com qualidade, não só se mostra insuficiente como por vezes é irrelevante, mostrando-se a sociedade na maioria das vezes a ela indiferente, uma vez que tal medida legislativa vem desacompanhada de todo o aparato que lhe daria sustentação.

Para Jean Cruet em sua obra A vida do Direito e a Inutilidade das Leis, o Estado ao legislar exerce apenas mais uma forma de operar da sociedade; e, ao tratar do desempenho de sua função legislativa, pontua o autor a necessidade de amadurecimento do remedeio para o objeto que se pretende tutelar. Vejamos:

\begin{abstract}
Sem dúvida o legislador tem o firme proposito de innovar, e, em cada uma das suas leis, julga as mais das vezes fazer de criador. Olhando, porém, de mais perto, percebe-se que a machina de fabricar leis gira no vacuo e não produz nada, quando não tem para moer o bom grão das ideias feitas e dos usos recebidos, quando não tem ao menos para amassar a materia prima d'uma concepção vigorosamente enraizada no espirito publico ou d'uma instituição largamente esboçada na prática. (CRUET, 1908, p. 165)
\end{abstract}

Ademais, no desempenho de sua função política, sua atividade deve ser direcionada prioritariamente a efetivar as reais necessidades da população, e, os detentores do poder de 
criar leis devem possuir uma aguçada percepção das necessidades sociais; utilizando-se de tal aparato normativo somente quando for realmente necessária a tipificação penal das condutas.

Encontramo-nos, dessa forma, em um sistema incoerente e a beira da ruína, uma vez que clama-se pelo recrudescimento da instituições penalizadoras e estas não possuem sequer espaço físico para alojar seus detentos; cria-se tipos penais incriminadores visando o encarceramento dos atores sociais desviantes do sistema, e, ao mesmo tempo, medidas despenalizadoras substitutiva às penas privativas de liberdade pois o sistema carcerário brasileiro já encontra-se superlotado e não tem estrutura para articular as atuais demandas existentes por encarceramento.

Além de carecer de validade social, uma proliferação legislativa desenfreada acaba também pondo em xeque a efetividade da possível aplicação da sanção contrariando o caráter intimidativo que a imposição de pena deveria exercer, uma vez que normas penais são produzidas para atender aos clamores sociais pelo recrudescimento do sistema, sem preocupar-se com a eficácia de sua aplicação.

Neste sentido, já prelecionava sabiamente o Cesare Beccaria que "Proibir uma grande quantidade de ações diferentes não é prevenir os delitos que delas possam nascer, mas criar outros novos; é definir arbitrariamente a virtude e o vício, que nos são apresentados como eternos e imutáveis.” (BECCARIA, 1999, p. 131), uma vez que, dessa forma, selecionase bens jurídicos a serem penalmente tutelados, que poderiam ser melhor geridos por outros formas de controle social, o que lhe traria mais coerência no enfrentamento do problema, sempre atento à realidade social.

Vale ainda relembrar que, como trazido por Virgílio Luiz Donnici:

\begin{abstract}
A planificação da defesa social obriga, necessariamente, ao exame e a reforma da legislação penal de cada país, que deve estar atento às realidades sociais. $\mathrm{Na}$ sociedade moderna não mais é admissível a imposição de simples imposição de sanções penais cada vez mais severas, em que pese os clamores da opinião pública exigindo medidas contra o aumento da criminalidade. (DONNICI, 1976, p. 94-95).
\end{abstract}

A certeza de punição é um desestímulo a prática do crime, entretanto, não importa o agravo da pena se não há efetividade na sua manipulação - uma vez que nos encontramos diante da elaboração de leis para simplesmente atender aos clamores sociais - pois não se resolve o problema do delito com a elaboração de leis. Se ora cria-se normas visando o encarceramento, diante dos clamores sócias por braços fortes do Estado, e posteriormente, não havendo estrutura institucional de penitenciárias para suprir tal demanda, cria-se também medidas cautelares substitutivas da prisão - fazendo com que os próprios criminosos saibam 
que pequenos crimes ficarão sujeitos apenas a medidas mais brandas - fica claro o descrédito na certeza da punição, pondo-se em xeque a efetividade do ordenamento jurídico penal.

Ao nos reportarmos mais uma vez ao clássico Do delito e das penas, deparamo-nos com a seguinte orientação:

Quereis prevenir os delitos? Fazei com que as leis sejam claras, simples e que toda a força da nação se concentre em defendê-las e nenhuma parte dela seja empregada para destruí-las. Fazei com que as leis favoreçam menos as classes dos homens do que os próprios homens. (BECCARIA, 1999, p. 131).

A proliferação desenfreada de normas penais com o intuito de controlar os conflitos sociais não se sustenta, pois acaba por desencadear a sucessão - e até mesmo o choque - de leis, acarretando em um ordenamento jurídico truncado e desalijado do mínimo de condição de efetivação das respectivas normas criadas.

Alerta Luiz Luisi que "a partir da segunda década do século XIX, as normas penais incriminadoras cresceram desmedidamente, a ponto de chamar a atenção de penalistas de diversas épocas" (2003, p. 40). Esse mesmo autor, ainda relata que Franz Von Listz, em 1896, já enfatizava que a legislação de seu tempo fazia um "uso excessivo da arma da pena"; e, traz também que Francesco Canelutti já falava em sua época, de "inflação legislativa”, fazendo a comparação de que seus efeitos seriam parecidos ao da inflação monetária - já que ocorreria uma desvalorização das leis penais com relação a sua eficácia preventiva geral -, chegando também a fazer menção a Carlos Enrico Parielo que falava em "crescimento patológico da legislação penal”. (LUISI, 2003, p. 41- 45)

E mais, Luiz Flávio Gomes e Antonio García-Pablos de Molina, reportando-se às sábias lições do Marques de Beccaria, trazem a baila:

Não faltava razões, portanto a Beccaria quando sustentava já em 1764 que o decisivo não é a gravidade das penas, senão a rapidez (imediatidade) com que são aplicadas; não o rigor ou a severidade do castigo, senão a sua certeza e infalibilidade: que todos saibam e comprovem - incluindo o infrator potencial, dizia o autor - que o cometimento do delito implica, inevitavelmente na pronta imposição do castigo. (MOLINA, GOMES, 2008, p.361). 
Assim temos de que nada adianta uma série interminável de leis penais que se sucedem - e que às vezes até mesmo se indispõem umas com as outras - se elas não demonstram-se infalíveis no momento de sua aplicação. $\mathrm{O}$ caráter preventivo ${ }^{2}$ que pode ser auferido do sistema penal, desempenhado pelas leis que cominem penas mais atrozes aos delitos, diante dos clamores sociais, está exatamente na sua pronta aplicação após o devido processo legal, incutindo a intimidação aos potenciais infratores que se veriam desestimulados a praticarem infrações diante da certeza da pena. Temos assim, segundo Cesar Beccaria que “Quanto mais a pena for rápida e próxima do delito, tanto mais justa e útil ela será.” (1999, p. 79).

Isto posto, não sejamos céticos a ponto de negar a potencial contribuição na prevenção do delito que o sistema penal, através da cominação de pena aos delitos, pode trazer ao controle social.

Conforme aduzem Antônio Garcia-Pablos de Molina e Luiz Flávio Gomes, "Nenhuma política criminal realista pode prescindir da pena; porém, tampouco cabe denegrir a política de prevenção, convertendo-a em mera política penal” (2008, p. 368), pois a utilização mais intensa do direito penal na eleição de uma política criminal não implica, necessariamente em menos crimes. Um equilíbrio entre políticas públicas basilares que atuem já nas causas do problema social é de fundamental importância, e, estas serão ainda mais efetivas se aliadas à intimidação desempenhada por uma legislação penal sólida consistente e compromissada com a realidade social.

Visível fica que o problema é complexo e que necessário faz-se uma solução conjunta de medidas eficazes em todos os âmbitos, devendo o sistema buscar operar como uma máquina que precisa de todas as suas engrenagens para funcionar com precisão. Dessa forma, a solução do problema estaria nas mãos de todos os âmbitos do poder, em que o cumprimento de políticas públicas destinadas à implementação de funções sociais do Estado, mostra-se como importante primeiro passo para que se efetive a prestação de serviços públicos eficientes e efetivos para a gestão de qualidade da segurança pública nacional.

Não há como esperar que o problema da segurança pública fosse solucionado pela criação de novos tipos penais, pela repressão através da atuação policial, ou pela atuação do sistema penal como um todo, pois tais medidas não se sustentam sozinha.

\footnotetext{
2 A respeito do caráter preventivo desempenhado pela pena, esclarece Beccaria que "[...] a presteza da pena é mais útil porque, quanto mais curto o tempo que decorre entre o delito e a pena, tanto mais estreita e durável no espírito humano é a associação dessas duas ideias, delito e pena; de tal modo que imprescindivelmente se consideram um como causa e a outra como efeito necessário e indefectível.” (BECCARIA, 1997, p. 80)
} 
Qualquer medida proposta deve estar sempre amparada por políticas públicas que a antecedam, pois uma política de segurança só tem efetividade diante de uma verdadeira política social interna bem definida que caminhe no mesmo ritmo das aspirações sociais. Tais medidas devem visar sempre menores intervenções do sistema penal quando se fizerem cabíveis outras medidas de políticas sociais eficientes no tratamento do problema, pois, mais uma vez volta-se a reafirmar que, o direito penal deve ser resguardado como ultima ratio, no tratamento dos conflitos sociais, dada a sua subsidiariedade em relação aos demais ramos do ordenamento jurídico.

Nas palavras de Eros Roberto Grau:

O Estado social legitima-se, antes de tudo, pela realização de políticas, isto é, programa de ação; [...] essas políticas, contudo, não se reduzem à categoria das políticas econômicas; englobam, de modo mais amplo, todo o conjunto de atuações estatais no campo social (políticas sociais). A expressão políticas públicas designa todas as atuações do Estado, cobrindo todas as formas de intervenção do poder público na vida social (1996, p.22).

Dentro desse conjunto de atuações estatais no campo social deveriam estar inseridos programas de ação nos mais variados setores sociais atuando de forma conjunta e integrada na missão da pacificação social. Entretanto, ao quedar-se omisso o Estado na missão de propiciar direitos básicos ao cidadão no campo social, acaba ele por depositar no sistema penal o remedeio dessa inércia; não destinando recursos, nem gerindo de forma adequada a prestação do serviço pública de segurança nacional, o que deságua na prestação de serviços públicos inadequados à realidade social vigente do atual sistema penal repressivo brasileiro.

\section{A SEGURANÇA PÚBLICA FORA DAS LENTES DE UM "ESTADO JURÍdICO NEÓFOBO”: PROPOSTAS DE SERVIÇOS PÚBLICOS EFICAZES NO TRATAMENTO DA REALIDADE SOCIAL FÁTICA}

Temos assim que, diante dessa atuação fragmentária exposta, mesmo na ausência de um modelo de gestão eficiente para a prestação do serviço público de segurança ofertado pelo Estado (que deposita no sistema penal repressivo toda a responsabilidade de garanti-la sem um arcabouço de políticas públicas que o dê sustentação), este continua insistindo nas mesmas ferramentas de outrora, demonstrando uma certa aversão a mudanças, ainda que isso 
demonstre ser extremamente necessário e positivo para o aperfeiçoamento da prestação do serviço público de segurança.

Neste diapasão, fica perceptível, até mesmo, o reinvestimento de mais recursos em repressão através do atual modelo reativo/repressivo utilizado, sem qualquer melhoria de resultados, o que não auxilia no aperfeiçoamento da prestação do serviço público de segurança, que mantêm os mesmos resultados práticos, tal qual se encontra, ainda que se destinem mais investimentos nele; sendo necessário, dessa forma, análises compromissadas afastadas de sensacionalismos que apregoam um sistema penal mais forte, pautado no aumento da repressão, como tábua de salvação. Vejamos:

\begin{abstract}
Destacamos que a segurança pública é, em realidade, um tema que merece os mais sérios e escolados apontamentos, não se podendo e nem se devendo admitir que venham certos "pesquisadores de plantão", os ditos "psicólogos", pois são estes que, mesmo não possuindo qualquer tipo de conhecimento sobre a matéria que se atrevem a dar certos pontapés, vêm, e ofertam os seus palpites, todos, em geral, ao acaso, cultivando, em muitas vezes, apenas o sensacionalismo e o seu poder de aparecer nos meios de comunicação de massa, o que faz com que os órgãos responsáveis pela Segurança Pública se vejam envolvidos em certas e determinadas situações inusitadas, que são as criadas por essas ditas pessoas. Vê-se que elas não se preocupam, de modo algum, com as repercussões de suas manifestações, como regra, todas inglórias. (BOTELHO, 2011, p. 185-186)
\end{abstract}

Nesse contexto, podemos notar uma falha científica na utilização do direito penal, que acaba por refletir em uma ideologia ${ }^{3}$ desviante do sistema penal de supervalorização da repressão conduzida pela errônea eleição do direito penal como importante meio de pacificação social - quando deveria ter apenas aplicação subsidiária -, sem perceber que tal escolha apenas mitiga o problema sem encará-lo de fato. Loïc Wacquant, ao deparar-se com tal problemática aponta essa falha ideológica do sistema penal:

O erro científico e cívico mais grave consiste, aqui, em crer e fazer as pessoas acreditarem - como apregoa o discurso da hiper-segurança que, hoje em dia, satura os campos políticos e midiáticos - que a gestão policial e carcerária é o remédio ótimo, o caminho real para a restauração da ordem sócio-moral na cidade, senão o único meio de garantir a „segurança" pública, e que não dispomos de nenhuma outra alternativa para conter os problemas sociais. (WACQUANT, 2007, p. 22-23)

\footnotetext{
3 Ideologia, de uma forma simples, é compreendida como "sistema de atitudes integradas de um grupo social -ideologia enquanto sistema de ideias relacionadas com a ação" (WOLKMER, 2000, p. 95), sendo o referido,caráter ideológico e repressivo do sistema penal brasileiro" verificado em relação às expectativas depositadas no sistema punitivo estatal como mordaz instrumento de controle social punitivo institucionalizado no anseio da sensação de maior segurança que um sistema punitivo forte e perspicaz possa a trazer, esperandose, consequentemente ações por parte das instituições do sistema penal nesse sentido. Reafirma-se, nesse contexto, que isso ocorre devido ao referido caráter ideológico que permeia o sentir e o pensar de parte considerável da sociedade que conclama essa forma repressiva de agir do sistema penal.
} 
Fica, com tudo isso, bastante visível a eleição política pela via da repressão, frente à prevenção do delito, preferindo-se abafar os „sintomas“e do problema o mais rápido possível, quando através da prevenção o problema poderia ser atacado em suas causas.

Winfried Hassemer com propriedade, acerca da interrelação que deve ocorrer entre todos os setores responsáveis pela pacificação social, afirma ainda que:

\begin{abstract}
Política de segurança pública não equivale à política policial, mas compreende também à política criminal que por sua vez, compreende não apenas ao ponto de vista da efetividade policial, mas também as garantias penais e constitucionais; o que mesmo assim é muito pouco.

[...], política pública sem consideração para com a juventude, a mão de obra, a moradia, os problemas sociais e a educação, converte-se num espetáculo sem esperança e sem fim previsível. Portanto, uma política de segurança só faz sentido no contexto de uma verdadeira política interna bem definida, sincronizada e coordenada. (HASSEMER, 1994, p. 32)
\end{abstract}

O sistema de segurança pública brasileiro tem se mostrado fragmentário. Além da não utilização das demais formas de controle social antes de se recorrer ao sistema penal, temos, dentro do próprio sistema, a verificação da mesma fragmentariedade quando observamos que cada corporação atua de forma independente e não tem qualquer ligação funcional com as outras, o que, além de as distanciarem, acaba, por vezes, criando animosidades e concorrência; ao invés de contribuírem $\mathrm{cm}$ o aperfeiçoamento da prestação dos serviços públicos de segurança.

Dessa forma, seria conveniente que aqueles "críticos de plantão" quando forem oferecer as suas manifestações noticiosas, devam se preocupar com a realidade dos fatos e com os resultados efetivos manifestados pelas Instituições Policiais, até para evitar danos irreparáveis àquelas, noticiando o fato verídico sem distorções e sem demagogia, o que contribuiria para o aperfeiçoamento do sistema de Segurança Pública. (BOTELHO, 2011, p. 186)

Por todo o exposto, é inegável que o valor da segurança pública tem ganhado especial destaque na atualidade devido aos níveis alarmantes de violência e criminalidade que afetam a ordem pública e a convivência social pacífica. Assim, nota-se facilmente elevada demanda social por uma atuação mais eficiente e eficaz dos mecanismos de proteção estatal na consecução de um serviço público adequado para a consolidação do correto gerenciamento a adoção de uma política de segurança pública adequada, da qual é possível extrair a necessidade de melhorias no nível de segurança pública decorrentes do próprio medo coletivo da violência, que é apontado como um dos fatores de legitimação para o aumento da repressão do Estado. 
Tal sistemática leva a corroborar que o tema segurança pública, tradicionalmente relegado a segundo plano, merece ganhar espaço e importância no cenário jurídico, conforme assevera Valter Foleto Santin (2013, p.09) - devido aos crescentes apelos da sociedade assombrada pelos problemas causados em decorrência do descontrole da criminalidade tornando indispensáveis as atenções dos estudiosos para essa importante área de atuação do Estado.

Segundo Azor Lopes da Silva Júnior (2014, p. 108), não é de agora que sustenta-se a necessidade de uma revisão de paradigmas na área de segurança pública que possibilite encarar os conflitos sociais por uma ótica transdisciplinar, capaz de orientar sua solução ou condução com o auxílio de outras ciências que não só a jurídica; mas os paradigmas que permeiam a ordem burocrática estatal, notadamente os de natureza jurídica, fazem a estrutura estatal permeável, quando não reativa, às propostas de mudança: um Estado Jurídico Neófobo, segundo ele. (SILVA JÚNIOR, 2014, p. 108)

Assim, primordial demonstra ser a realização de uma análise acerca da atual conjuntura de resposta aos conflitos sociais e criminais dadas de forma privativa pelo judiciário, via de regra tardiamente e pautada em legislações que não mais atendem às expectativas dos cidadãos envolvidos em conflitos sociais; podendo estas acarretarem, inclusive, o agravamento de situações simples, pois a descrença na eficiência do Estado tem levado pessoas a aplicarem suas próprias justiças.

Isso porque a segurança pública e por derivação a "sensação de segurança", é um direito constitucional de cada cidadão, logo, é dever do Estado prover essa necessidade bem como buscar mecanismos que atinjam essa meta, saindo assim do comodismo e insatisfações atuais, para que novos caminhos sejam trilhados.

Tamanho tem sido a sua repercussão que segurança pública ganhou também status de bem coletivo, merecendo especial atenção no texto constitucional, e, Valter FoletoSantin (2005, p. 208-216) retrata ainda as características de direito ou interesse difuso da segurança pública. Conforme previsto no artigo 144 da Constituição Federal “a Segurança Pública é dever do Estado, direito e responsabilidade de todos", sendo delegada aos estados-membros esta incumbência, por meio de suas polícias.

No tocante às mudanças necessárias para o aperfeiçoamento do atual sistema, Marcos Rolim, traz interessante metáfora para evidenciar o modelo reativo-repressivo de gestão da segurança pública adotado: 


\begin{abstract}
Uma metáfora apresentada por Sherman talvez sintetize bem o significado da mudança necessária. Para ele, a polícia estaria desenvolvendo um trabalho seguindo um atendimento de emergência ("modelo hospitalar"). Ocorre que este modelo é inapropriado para o controle do crime. Os hospitais são organizações reativas que esperam os doentes. Eles existem para curar doentes, não para controlar a doença. Já as agências públicas de saúde não recebem pacientes, mas buscam controlar e acabar com as doenças. Sendo assim, a gestão do trabalho policial deveria estar preocupada com a análise do crime, sua cadeia de causalidade e as tendências epidemiológicas emergentes. (ROLIN, 2006, p.65-66)
\end{abstract}

Assim, para ilustrar o modelo reativo de policiamento, a metáfora utilizada por Sherman comparando o modelo reativo de policiamento com o atendimento hospitalar emergencial evidencia que tal modelo é visivelmente inapropriado para o controle do crime. Em tal metáfora, temos o fato de que hospitais são organizações reativas; constituindo-se em instituições que apenas esperam os doentes chegarem até ela; existindo para tratar da cura dos doentes depois de doentes, e não para controlar a doença.

Da mesma forma, ocorre com a gestão do trabalho policial que deveria estar preocupada com a análise do crime, sua cadeia de causalidade e as tendências epidemiológicas emergentes; e não é assim que está estruturado o modelo de gestão para a prestação dos serviço público de segurança, que ocorre justamente da forma contrária.

Como proposta viável complementar e alternativa a essa dinâmica atual pouco eficiente, dentre os instrumentos metodológicos desenvolvidos para a prevenção da violência e a construção de uma cultura de paz, destaca-se, por exemplo, a mediação de conflitos, que deve ser entendida como um mecanismo mais amplo de desconstrução de conflitos, destinado a transformar padrões de comportamento e a estimular o convívio em um ambiente cooperativo, no qual os conflitos possam ser tratados sem confronto e de modo não adversarial.

Para construir uma cultura de paz é preciso mudar de atitudes, crenças e comportamentos, reconhecendo no conflito um trampolim para o desenvolvimento, buscando, nem sempre, a sua eliminação, mas sim, modos criativos, não violentos e multifuncionais de resolvê-los. Por meio dessa técnica, as partes direta e indiretamente envolvidas no conflito tem a oportunidade de refletir sobre o contexto dos seus problemas, de compreender as diferentes perspectivas e, ainda, de construir em comunhão uma solução que possa garantir, para o futuro, a pacificação social.

A mediação comunitária surge como uma fomentadora do respeito, participação e cultura de paz. Tudo isso se daria mediante técnicas e procedimentos operativos informais (desinstitucionalizados), em favor de uma Justiça que pretende resolver o conflito, dar satisfação à vítima e à comunidade, pacificar as relações sociais 
interpessoais e gerais danificadas pelo delito e melhorar o clima social: sem vencedores nem vencidos, sem humilhar nem submeter o infrator às "iras da lei", nem apelar à “força vitoriosa do Direito”. (MENDONÇA 2006, p. 36)

Nesta perspectiva, a intenção da presente pesquisa é demonstrar que os atuais modelos convencionais não conseguem mais lidar de forma eficaz com a escalada da violência e do crime e não mais atendem aos anseios sociais, de forma a impulsionarem a necessidade de transformações mais amplas na vida social contemporânea, principalmente nas diferentes formas dos indivíduos se organizarem, governarem a si mesmos e aos outros para dar conta da complexidade e da fragmentação da realidade social da segurança pública brasileira; o que guarda estreita correlação com a sistemática global da obra de Fernando de Brito Alves (2013) ao tratar de Constituição e Participação Popular.

Isso porque, com a disseminação de tal prática temos o reforço da cultura de paz, através do estímulo ao diálogo e da solução pacífica dos casos em disputa, o que é extremamente benéfico para a pacificação social, como um todo, em suas várias vertentes.

Gianpaolo Poggio Smanio e Humberto Barrinuevo Fabretti novamente trazem a baila a ideia de intervenção penal mínima como importante mecanismo de racionalização do sistema. Vejamos:

\begin{abstract}
A ideia da intervenção mínima pode, em uma primeira leitura, sugerir que o Estado Democrático de Direito interesse apenas a redução pura e simples da incriminação da apenação. Isso, entretanto não é verdade. Uma intervenção repressiva orientada pela ideologia do Estado Democrático de Direito importa na redução da incriminação e da apenação ao estritamente necessário. A utilização do Direito Punitivo deve ser sempre limitada e orientada pelos objetivos de realização de interesses sociais maiores (2010, p. 161).
\end{abstract}

Dessa forma, deve o sistema punitivo do Estado ser orientado pela realização de interesses sociais maiores, respaldando-se em políticas públicas fortes, eficazes, bem definidas e passíveis de efetivação. Não se soluciona a problemática do delito através da criação de leis; pois a mudança na seara normativa, dissociada dos demais aparelhos de contenção da criminalidade, é irrelevante, e até mesmo a própria sociedade, na maioria das vezes, se mostra indiferente a ela, pois a elaboração desenfreada de leis penais, como já trazido anteriormente, acarreta uma espécie de "inflação legislativa", que ocasiona a desvalorização das leis penais, uma vez que perde o seu sentido coercitivo de ultima ratio. Nas palavras de Carlos Alberto Baptista temos que: 
Para a alteração da atual crise de insegurança social não se faz necessária a criação de novos organismos ou estruturas sociais. Inicialmente, o processo cultural comprometido com os ideais de poder, controle e alienação deve ser deixado de lado, fazendo com que se ponha em prática o que só se vê na teoria: políticas públicas fortes, com objetivos definidos e, acima de tudo, passíveis de efetivação. Caso contrário, o empenho não ultrapassará a retórica dos discursos. (BAPTISTA, 2007, p. 126)

Dessa forma, conforme preleciona Fernando Galvão "se o Direito Penal deve restringir sua interferência ao mínimo necessário, a força punitiva da intervenção deve ser bem orientada para produzir os melhores resultados possíveis.” (GALVÃO, 2007, p. 76-77). O problema da criminalidade deve ser enfrentado com uma política criminal bem definida, séria, que busque, antes de tudo, encarar toda a problemática criminal sem passionalismos.

O homem vive e sofre as influências do meio social em que está inserido; e as leis penais, por si só, não são suficientes para reprimir o crime. Assim, sendo o crime um ato humano que possui relações com a ordem econômica, política e social vigente; visível fica que, a mudança na seara normativa e executiva, conduzida por mais repressão, dissociada dos demais aparelhos de contenção da criminalidade certamente se demonstrará inócua; ficando visível que tal mecanismo de produção exacerbada de uma normatização penal mais severa, bem como a prestação de serviços públicos de segurança com foco primordial voltado para a via reativo-repressiva, não funciona como fator inibidor da prática de infrações penais.

Outra metáfora também bastante interessante com relação aos modelos de gestão da segurança pública majoritariamente utilizados na modernidade é a que explora o esforço de "nadar contra a correnteza o tempo todo, o que demanda um esforço descomunal, quando o ideal seria ter foco em propostas menos desgastantes e mais eficazes no tratamento da problemática em pauta.

\footnotetext{
Quando pensamos no papel desempenhado pelas polícias no mundo moderno, o maior desafio é o de superar um modelo pelo qual os policiais se obrigam a "nadar" todo o tempo, normalmente com resultados muito limitados porque, quando são avisados, isso é sinal de que "as crianças já estão afogadas". As propostas em favor do policiamento comunitário (PC) e do policiamento orientado para a solução de problemas (Posp) partem do pressuposto de que é preciso procurar o que está acontecendo antes daquele ponto da "correnteza". (ROLIN, 206, p. 67)
}

A tendência mais moderna, voltada para a pacificação de conflitos é a possibilidade de se encarar os conflitos sociais por uma ótica transdisciplinar que vai além dos liames convencionais já tanto tempo eleitos para gerirem a prestação do serviço de segurança pública nacional, buscando desonerar e melhor operacionalizar tanto o sistema quanto a atual e vigente sistemática de prestação dos serviços públicos relacionados a segurança pública, 
sendo capaz de orientar a sua solução ou condução com o auxílio de outras ciências que não só a jurídica.

Entretanto, como já relatado, segundo Azor Lopes da Silva Júnior (2014, p.108) os paradigmas que permeiam a ordem burocrática estatal - os de natureza jurídica, inclusive -, tornam a estrutura estatal bastante fragilizada, quando não até mesmo reativa, às propostas de mudança, o que tal autor designa como as bases deum “Estado Jurídico neófobo”. E repete-se, novamente, que não é de agora que se sustenta a necessidade de uma revisão de paradigmas na área de segurança pública que possibilite encarar os conflitos sociais por uma ótica transdisciplinar, capaz de orientar sua solução ou condução com o auxílio de outras ciências que não só a jurídica (SILVA JÚNIOR, 2014, p. 108).

Em suas palavras “os paradigmas que permeiam a ordem burocrática estatal, notadamente os de natureza jurídica, fazem a estrutura estatal permeável, quando não reativa, às propostas de mudança: um Estado jurídico neófobo”. (SILVA JÚNIOR, 2014, p. 108) que tem uma espécie de aversão a mudanças, e, na maioria das vezes insiste em não evoluir na adoção de novos paradigmas.

E é partindo deste pressuposto e seguindo nesta linha de raciocínio, que surgem estudos direcionados para práticas tais como as de polícia comunitária; policiamento orientado a solução de problemas que são os POSP's, o de uma justiça restaurativa, entre outras, em contraponto com o modelo convencional de uma justiça criminal

A prevenção no âmbito de tarefas específicas de policiamento pode ser realizada com sucessotambém através de estratégias corretas de policiamento que abrem debate para matizes como o policiamento comunitário, dentre outras técnicas, e daí a defesa dos CONSEGs (Conselhos Comunitários de Segurança), como uma alternativa viável para a melhoria da prestação dos serviços públicos de segurança, uma vez que possibilita e a alia a participação popular para uma adequada e satisfatória forma de resolução de conflitos. Vejamos:

A filosofia de policiamento comunitário parte da premissa de que a identificação e a solução dos problemas relacionados à violência numa dada localidade devem ser compartilhadas com a população. Sua implementação, portanto, requer uma mudança do paradigma secularmente adotado pelas polícias militares, que valoriza o enfrentamento no lugar da prevenção e da ,produção policial ${ }^{\text {ee }}$, traduzida em prisões e apreensões, no lugar da mediação de conflitos e da adoção de formas adequadas de resolução dos problemas. É importante refletir também de que forma a participação popular está sendo interpretada e vivenciada nos conselhos de segurança sob a ótica dos policiais, num contexto onde, como ressaltado acima, o discurso e a ideologia ainda vigente sobre o trabalho policial valoriza mais "pessoas presas" e "coisas apreendidas", em detrimento do diagnóstico e da resolução adequada dos problemas cotidianos que geram insegurança, em conjunto com a população. (MORAES, 2009, p.20) 
Tais conselhos, na gestão para uma melhor prestação do serviço público de segurança representa interessantíssimo reflexo de um novo paradigma de democratização na segurança pública brasileira e este encontra fundamento e vem estampados no Programa Nacional de Direitos Humanos 3 - PNDH-3/2009, que trazem a democratização e a modernização do sistema de segurança pública, aliada a participação popular (Decreto 7.037/09, Eixo Diretor IV, diretrizes 11 a 16).

Em busca de novos paradigmas, Eduardo Cambi (2011, p.115) traz à baila o combate e a negação de direitos por critérios meramente formais; tecendo críticas aos métodos de coerção e restrição de direitos e apregoando a valorização do conteúdo em detrimento do apego excessivo a forma em uma teoria crítica do processo, o que também pode contribuir sobremaneira com o proposto sistema multiportas em consonância com o direito pós moderno apregoado. Assim temos que:

[...] o direito pós-moderno combate a negação de direitos por critérios meramente formais, privilegiando o conteúdo em detrimento do apego excessivo a forma. Critica os métodos de coerção e restrição de acesso a direitos, baseado no império do rito, do procedimento, do acesso condicionado pela burocracia, que fazem com que o direito seja acessível tão somente àqueles que sobrevivem às armadilhas e as artimanhas criadas pelo sistema jurídico. (CAMBI, 2011, p.115-116)

Dessa forma, alinhados a toda essa demanda de necessidade do estabelecimento de novos paradigmas gestores da segurança pública, os conselhos comunitários de segurança pública destinam-se exatamente, em última estância, a transformar a realidade da tomada de decisões políticas aliando a participação popular nos rumos das decisões a serem tomadas no campo da segurança pública, de forma que estas passem a atender as reais expectativas da população e atue de forma integrada com a realidade da população atendendo aos anseios sociais vigente - o que certamente contribui positivamente na prestação do serviço público de segurança, ao vencer suas "síndromes" e o seu neofobismo, em insistir em modelos gestores perceptivelmente inviáveis para a obtenção de melhores resultados. 


\section{CONSIDERAÇÕES CONCLUSIVAS}

Delineia-se, dessa forma, o insucesso do atual modelo reativo de gestão da segurança pública nacional e sua consequente ineficácia no tratamento da problemática crescente dos conflitos sociais, panorama no qual se deu a análise da política pública de segurança brasileira, tendo buscado, dessa forma, ambientar a prestação de tal serviço público para posterior posicionamento acerca da sua ineficiência; chegando, enfim, auma proposta que aliasse mais qualidade à prestação do serviço de segurança publica, com foco prioritário na efetiva pacificação social de conflitos.

Com isso, sustenta-se, por todo o exposto, a necessidade de uma revisão de paradigmas na área de segurança pública que possibilite encarar os conflitos sociais por uma ótica transdisciplinar.

Ao afirmar que "não é mais possível tratar o corpo da segurança pública apenas sintomaticamente", evidentemente chama-se a atenção para a falha da opção reativorepressiva enveredada pelo Estado, que ao sobrecarregar seu sistema penal repressivo, apenas remedeia as manifestações de conflito social, sem encará-las de fato. Visualiza-se, assim, que o Estado acaba, na maioria das vezes, optando por cuidar apenas dos sintomas manifestados através do delito - e faz isso depositando, de pronto, nas costas da atividade policial repressiva a obrigação de responsabilizar-se pela contenção do delito -, o que acaba por desencadear a movimentação de toda a estrutura clássica da máquina judicial, sem antes buscar alternativas em outras formas de controle social que visem atingir o problema em suas causas e raízes.

Constatada tal neofobia jurídica estatal no tocante ao modelo gestor da segurança pública nacional, temos ainda que qualquer mudança - ou insistência no reinvestimento de verbas públicas em paradigmas repressivos - desalijada de uma eficiente prestação de serviços públicos de segurança com qualidade e dissociada de alterações nos demais aparelhos de contenção da criminalidade, não só se mostra insuficiente como por vezes é irrelevante;o que faz com que a sociedade se mostre, na maioria das vezes, indiferente a elas, uma vez que tais medidas vem desacompanhada de todo o aparato que lhe daria sustentação para uma efetiva pacificação social.

A proliferação do discurso repressivo, que faz com que muitas expectativas da sociedade civil recaiam sobre o sistema penal, é, na maioria das vezes, conduzida pelos campos político e midiático, demonstrando a falta de interesse em, de fato, enfrentar o 
problema em suas causas. Não há dúvidas de que é politicamente mais atraente reprimir prontamente o crime praticado - como forma de demonstrar atitude no combate ao delito -, quando na verdade, dever-se-ia optar por sua prevenção, que, entretanto, não atrai holofotes por surtir efeitos apenas a médio e longo prazo, quando atualmente vige a política do imediatismo.

Tal alternativa que se apresenta pela via preventiva - considerada um desafio que requer inúmeros avanços na prestação do serviço público de segurança atual - é uma tarefa muito mais árdua que a primeira, pois implicam em prestações positivas, contribuições e esforços solidários que devem buscar neutralizar as situações de desequilíbrio e conflitos sociais através de medidas efetivas no enfrentamento das causas do problema.

Como trazido no decorrer de toda a pesquisa, não é de agora que sustenta-se a necessidade de uma revisão de paradigmas na área de segurança pública que possibilite encarar os conflitos sociais de forma a melhor operacionalizar o sistema, tratando transdisciplinarmente da gestão do sistema penal brasileiro, de forma que este seja capaz de orientar sua condução com o auxílio de outras ciências que não só a jurídica; aliando, também, outros paradigmas que permeiam a ordem burocrática estatal, e, buscando, assim, enxergar novas propostas de mudança que cindam com o neofobismo do Estado no tocante à segurança pública.

Isso porque encontramo-nos em um sistema incoerente e a beira da ruína, uma vez que clama-se pelo recrudescimento da instituições penalizadoras e estas não possuem sequer espaço físico para alojar seus detentos; cria-se tipos penais incriminadores visando o encarceramento dos atores sociais desviantes do sistema, e, ao mesmo tempo, medidas despenalizadoras substitutiva às penas privativas de liberdade pois o sistema carcerário brasileiro já encontra-se superlotado e não tem estrutura para articular as atuais demandas existentes por encarceramento.

Assim, além de carecer de validade social, tal sistemática reativo-repressiva acaba também pondo em xeque a efetividade da possível aplicação da sanção penal, contrariando o caráter intimidativo que a imposição de pena deveria exercer, uma vez que normas penais são produzidas para atender aos clamores sociais pelo recrudescimento do sistema, sem preocupar-se com a eficácia de sua aplicação.

Averigua-se, dessa forma, que para construir uma cultura de paz é preciso mudar de atitudes, crenças e comportamentos, reconhecendo no conflito um trampolim para o desenvolvimento, buscando, nem sempre, a sua eliminação, mas sim, modos criativos, não 
violentos e multifuncionais de resolvê-los. E é nessa toada que, dentre os instrumentos metodológicos desenvolvidos para a prevenção da violência e a construção de uma cultura de paz, destaca-se, por exemplo, - como trazido no decorrer da pesquisa -, a mediação comunitária de conflitos, que deve ser entendida como um mecanismo mais amplo de desconstrução de conflitos, destinado a transformar padrões de comportamento e a estimular o convívio em um ambiente cooperativo, no qual os conflitos possam ser tratados sem confronto e de modo não adversarial.

Enfim, é por todo o exposto que propostas como a da mediação comunitária de conflito e a da valorização de conselhos comunitários de segurança pública destinam-se a transformar a realidade da tomada de decisões políticas aliando a participação popular aos rumos das decisões a serem tomadas no campo da segurança pública, de forma que estas passem a atender as reais expectativas da população e atue de forma integrada com a realidade da população atendendo aos anseios sociais vigente, que, ao vencer o neofobismo do Estado, contribuirá sobremaneira para a melhor operacionalização da prestação do serviço público de segurança brasileiro.

\section{REFERÊNCIAS BIBLIOGRÁFICAS}

ALVES, Fernando de Brito. Constituição e participação popular: a construção históricodiscursiva do conteúdo jurídico político da democracia como direito fundamental. Curitiba: Juruá, 2013.

BAPTISTA, Carlos Alberto. Crescimento da Criminalidade e Atuação Estatal. Curitiba: Juruá, 2007

BECCARIA, Cesare Bonessana, Marchesi de. Dos Delitos e das Penas. Tradução: Lucia Guidicini, Alessandro Berti Contessa. São Paulo: Martins Fontes, 1999.

BITENCOURT, César Roberto. Tratado de Direito Penal, volume 1: parte geral. 14. ed. São Paulo: Saraiva, 2009.

BOTELHO, Roberto. As Polícias Militares do Brasil e o Sistema Nacional de Segurança Pública, no Estado Democrático de Direito. In: COSTA, Ilton Garcia. RAMOS, Dirceu Torrecillas. ROTH, Ronaldo João. (Coord.). Direito Militar: doutrina e aplicações. 1. Ed. Rio de Janeiro: Elsevier, 2011.

CAMBI, Eduardo. Neoconstitucionalismo e Neoprocessualismo: direitos fundamentais, políticas públicas e protagonismo judiciário. 2. ed. ver. e atual. - São Paulo: Revista dos Tribunais, 2011. 
COSTA, Ilton Garcia. RAMOS, Dircêu Torrecillas. ROTH, Ronaldo João. (Coord.). Direito Militar: doutrina e aplicações. 1. Ed. Rio de Janeiro: Elsevier, 2011.

CRUET, Jean.A Vida do Direito e a Inutilidade das Leis. Livraria editora, Lisboa: 1908.

DONNICI, Virgílio Luiz. A Criminologia na administração da justiça criminal: sistemas judicial, policial, penitenciário. 2. Ed. ver. e aum. Rio de Janeiro: Forense, 1976.

FlORÊNCIO FILHO, Marco A.Abolicionismo X Direito Penal Mínimo: A doutrina garantista com opção para a (RE) Legitimação do Sitema Penal. Revista Ideia Nova. Ano 5, n. 3. Recife: Editora Nossa Livraria, 2007.

GALVÃO, Fernando. Direito Penal. 2. Ed. Belo Horizonte: Editora Del Rey, 2007.

GRAU, Eros Roberto. O direito posto e o direito pressuposto. São Paulo: Malheiros, 1996.

HASSEMER, Winfried. Segurança Pública no Estado de Direito. Revistade Direito Alternativo. São Paulo: Acadêmica, n.3, p. 20-34, dez. 1994.

KAZMIERCZAK, Luiz Fernando. Direito Penal Constitucional e Exclusão Social. Porto Alegre: Nuria Fabris Editora, 2010.

LAZZARINI, Alvaro. Direito administrativo da ordem pública. 3. ed. Rio de Janeiro: Forense, 2000.

LUISI, Luiz. Os princípios constitucionais penais. 2. ed.Porto Alegre: Sergio Antonio Fabris Editor, 2003.

MELlO, Celso Antônio Bandeira de. Curso de Direito Administrativo. 28. ed. São Paulo: Malheiros, 2010.

MENDONÇA, Ângela Hara Buonomo. Mediação Comunitária. Uma ferramenta de acesso à justiça? Tese de Mestrado em História Política e Bens Culturais. Fundação Getúlio Vargas. Rio de Janeiro, 2006

MOLINA,Antonio García-Pablos de. GOMES, Luiz Flávio.Criminologia: introdução a seus fundamentos teóricos e às bases criminológicas da Lei 1099/95, lei dos juizados especiais criminais. $6^{\circ}$. ed. reform., atual, e ampl. São Paulo: Revista dos Tribunais, 2008.

MORAES, Bismael B. (Cord.). Segurança Pública e direitos individuais. São Paulo: Juarez de Oliveira, 2000.

MORAES, Luciane Patrício Braga de. Pesquisa Nacional dos Conselhos de Segurança Pública. Brasília: Ministério da Justiça, 2009.

PIETRO, Maria Sylvia Zanela Di. Direito Administrativo. 24. ed.São Paulo: Atlas, 2011.

ROLIM, Marcos.A Síndrome da Rainha Vermelha: Policiamento e Segurança Pública no século XXI. Rio de Janeiro: Zahar; Oxford, Inglaterra: University of Oxford, Centre of Brasilian Studies, 2006. 
SANTIN, Valter Foleto. Característica de direito ou interesse difuso da segurança pública. Argumenta: Revista do Programa de Mestrado em Ciências Jurídicas, da Universidade Estadual do Norte do Paraná. v. 5, p. 208-216. UENP: Jacarezinho, 2005.

.Controle judicial da segurança pública: eficiência do serviço na prevenção e repressão ao crime. $2^{\text {a }}$. ed. São Paulo: Editora Verbatim, 2013.

SILVA, De Plácido E. Vocabulário Jurídico. 15. Ed.Rio de Janeiro: Forense, 1999.

SILVA JÚNIOR, Azor Lopes da. A sociedade em conflito e o Estado jurídico neófobo: Núcleos de Mediação Comunitária - São José do Rio Preto, SP. Revista do Laboratório de Estudos da Violência da UNESP, Marília: 2014.

SMANIO, Gianpaolo Poggio. FABRETTI, Humberto Barrionuevo. Introdução ao direito penal: criminologia, princípios e cidadania. São Paulo: Atlas, 2010.

WACQUANT, Loïc. Os condenados da cidade: estudos sobre marginalidade avançada. Trad. de João Roberto Martins Filho. Rio de Janeiro: Renavan, 2005.

WOLKMER, Antônio Carlos. Ideologia, Estado e direito. 3. Ed. ver. e ampl. São Paulo: Revista dos Tribunais, 2000.

ZAFFARONI, Eugenio Raúl. OLIVEIRA, Edmundo. Criminologia e política criminal. Rio de Janeiro: GZ Ed., 2010.

ZAFFARONI, Eugenio Raúl. OLIVEIRA, Edmundo. Criminologia e política criminal. Rio de Janeiro: GZ Ed., 2010. 